\title{
15 kDa Granulysin versus GM-CSF for monocytes differentiation: analogies and differences at the transcriptome level
}

\author{
Luciano Castiello ${ }^{1}$, David F Stroncek ${ }^{1 *}$, Michael W Finn², Ena Wang ${ }^{3}$, Francesco M Marincola ${ }^{3}$, Carol Clayberger ${ }^{2}$,
} Alan M Krensky ${ }^{2}$ and Marianna Sabatino ${ }^{1}$

\begin{abstract}
Background: Granulysin is an antimicrobial and proinflammatory protein with several isoforms. While the $9 \mathrm{kDa}$ isoform is a well described cytolytic molecule with pro-inflammatory activity, the functions of the $15 \mathrm{kDa}$ isoform is less well understood. Recently it was shown that $15 \mathrm{kDa}$ Granulysin can act as an alarmin that is able to activate monocytes and immature dendritic cells. Granulocyte Macrophage Colony Stimulating Factor (GM-CSF) is a growth factor widely used in immunotherapy both for in vivo and ex vivo applications, especially for its proliferative effects.

Methods: We analyzed gene expression profiles of monocytes cultured with 15 kDa Granulysin or GM-CSF for 4, 12, 24 and 48 hours to unravel both similarities and differences between the effects of these stimulators.

Results: The analysis revealed a common signature induced by both factors at each time point, but over time, a more specific signature for each factor became evident. At all time points, $15 \mathrm{kDa}$ Granulysin induced immune response, chemotaxis and cell adhesion genes. In addition, only $15 \mathrm{kDa}$ Granulsyin induced the activation of pathways related to fundamental dendritic cell functions, such as co-stimulation of T-cell activation and Th1 development. GM-CSF specifically down-regulated genes related to cell cycle arrest and the immune response. More specifically, cytokine production, lymphocyte mediated immunity and humoral immune response were down-regulated at late time points.
\end{abstract}

Conclusion: This study provides important insights on the effects of a novel agent, $15 \mathrm{kDa}$ granulysin, that holds promise for therapeutic applications aimed at the activation of the immune response.

\section{Background}

Many immunotherapies are based on the use of immunomodulators for the activation or suppression of the immune response. These immunomodulators include cytokines, chemokines and growth factors that act on specific subsets of immune cells in vivo or ex vivo, alone or in combination, to modulate an immune response.

GM-CSF is a growth factor encoded by the CSF2 gene [1]. It is a glycoprotein naturally produced by lymphocytes and monocytes that induces the ex vivo proliferation of hematopoietic progenitor cells to form colonies of mature blood cells[2]. In addition, GM-CSF induces the

\footnotetext{
* Correspondence: DStroncek@cc.nih.gov

${ }^{1}$ Cell Processing Section, Department of Transfusion Medicine, Clinical

Center, National Institutes of Health, Bethesda, MD 20892, USA

Full list of author information is available at the end of the article
}

proliferation of monocytes-macrophages and secretion of inflammatory cytokines such as tumor necrosis factor (TNF) and interleukin 1 (IL-1) [3]. It plays an important role in the activation of dendritic cells (DCs), T cells and natural killer (NK) cells[2]. Because of its role in modulating both the innate and adaptive immune responses, GM-CSF has been used for immunotherapies both in vivo and ex vivo. In vivo alone and in combination with other cytokines, it enhances antigen presentation of cancer cells $[4,5]$ and stimulates autologous immune responses [1,2]. It has also been used as a tumor vaccine adjuvant [1]. Ex vivo applications of GM-CSF are mainly related to the differentiation of monocytes into immature DCs in combination with IL-4 [6], IL-15 [7], interferon $\alpha$ (IFN- $\alpha$ ) [8], or as a single agent [9]. At a molecular level, GM-CSF induces monocyte expression of IL-10 [10],

\section{() BiolMed Central}


IL-3R [11], CD23 (FCER2) [12], CD1 [13] and regulates the expression of MHC class II antigens [14]. However, the molecular effects of GM-CSF on monocytes in vitro have not yet been completely characterized.

Granulysin is a member of the saposin-like protein (SAPLIP) family [15] and colocalizes in the granular compartments of human cytotoxic T lymphocytes (CTL) and NK cells along with granzymes and perforin [16]. It is encoded by GNLY and is a glycoprotein with at least 4 different isoforms [15]. The "mature" granulysin protein $(9 \mathrm{kDa})$ results from the proteolytic maturation of a "secretory" $15 \mathrm{kDa}$ precursor. The $9 \mathrm{kDa}$ isoform is a well characterized proinflammatory cytokine with cytolitic activity [17]. It is able to induce cytolysis of various types of tumors and microbes and induces the expression of several cytokines, such as CCL5 (RANTES),

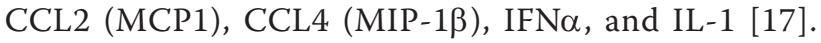
The $15 \mathrm{kDa}$ protein is constitutively secreted but its physiological roles have only recently been elucidated [18]. Several diseases, including infections, cancer, autoimmune and skin ailments, are characterized by an abnormal level of expression of Granulysin, suggesting a possible role in regulating immune response and the normal physiology [17]. Recently it has been shown that both 9 and $15 \mathrm{kDa}$ recombinant Granulysin are able to activate antigen presenting cells and act as immune alarmins [18]. In fact, they induced in vitro chemotaxis and activation of both human and mice DCs and inflammatory leukocytes [18]. Of note, $15 \mathrm{kDa}$ Granulysin is much more potent in chemotaxis and proinflammatory activities than the $9 \mathrm{kDa}$ isoform [18] and while the $9 \mathrm{kDa}$ isoform is a potent antimicrobial and tumoricidal agent, the $15 \mathrm{kDa}$ form has no cytolytic activity in vitro (Clayberger et al., submitted for publication).

In the present study, we performed gene expression analysis of monocytes cultured for 4, 12, 24 and 48 hours in presence of either GM-CSF or $15 \mathrm{kDa}$ Granulysin. This analysis showed that a common signature could be identified at each time point, but over time, different specific effects could be assigned to each of the cytokines relevant to monocyte differentiation and potential therapeutic use. In particular, GM-CSF specifically modulated the expression of several genes involved in the cell differentiation, whereas Granulysin specifically induced the expression of proinflammatory cytokines.

\section{Methods}

\section{$15 \mathrm{kDa}$ Granulysin expression and purification}

A detailed description of the procedure has been previously described by Finn et al, 2011 [19]. Briefly, a cDNA clone of the $15 \mathrm{kDa}$ Granulysin gene was generated from human peripheral blood cells and cloned into a pet $28 \mathrm{~A}$
E. coli expression vector. After being engineered for insect expression and secretion, the vector was transfected in $\mathrm{Hi} 5$ insect cells and after 2 days of culture at $21 \mathrm{C}$ the supernatant was filtered using a $0.45 \mu \mathrm{M}$ filter and applied to a $5 \mathrm{ml}$ HiTrap Heparin HP (GE Health Care, Uppsala, Sweden). Fractions containing the $15 \mathrm{kDa}$ Granulysin were pooled, purified on $1 \mathrm{ml}$ Resource $\mathrm{S}$ column (GE Health Care), concentrated and stored at $-80^{\circ} \mathrm{C}$.

\section{Cell Culture}

Human peripheral blood from three healthy donors was collected by apheresis in the Department of Transfusion Medicine of the Clinical Center (NIH) using Amicus Separator (Baxter Healthcare Corp., Fenwal Division, Deerfield, IL). The monocyte fraction was immediately separated by elutriation (Elutra ${ }^{\circledR}$, Gambro BCT, Lakewood, CO, USA) according to the manufacturer's instructions and the purity achieved was greater than $80 \%$. Fresh monocytes were cultured in 6-well plates (Corning Costar, Corning Incorporated, Corning, NY, USA) at a concentration of $2 \times 10^{6} \mathrm{cell} / \mathrm{ml}$ in $90 \%$ RPMI-1640 media, 10\% AB heat inactivated plasma, $10 \mathrm{mcg} / \mathrm{ml}$ gentamicin in the presence of $15 \mathrm{kDa}$ Granulysin (10 nM) or GM-CSF (Leukine Sagramostin, $10 \mathrm{ng} / \mathrm{ml}, 56 \mathrm{IU} / \mathrm{ml}$, Genzyme, Cambridge, MA, USA) and harvested at 4,12, 24 and 48 hours.

\section{RNA extraction}

At times $0,4 \mathrm{~h}, 12 \mathrm{~h}, 24 \mathrm{~h}$ and $48 \mathrm{~h} 20 \times 10^{6}$ cells from each culture condition were used for total RNA extraction using miRNA Easy Kits (Qiagen, Valencia, CA, USA). RNA quantity and quality were assessed by ND-1000 Spectrophotometer (NanoDrop Technologies, Wilmington, DE, USA) and Agilent 2100 Bioanalyser (Agilent Technologies, Waldbronn, Germany), respectively.

\section{Microarray Analysis}

Samples and universal Human Reference RNA (Stratagene, Santa Clara, CA, USA) were amplified and labeled using Agilent kit according to the manufacturer's instructions and hybridized on Agilent Chip (Whole Human genome, $4 \times 44 \mathrm{k}$, Agilent Technologies, Santa Clara, CA, USA). The arrays were scanned with Agilent Microarray Scanner and the images were analyzed using Agilent Feature Extraction Software 9.5.1.1. Resulting data were uploaded onto mAdb Gateway http://madb. nci.nih.gov, retrieved and analyzed with BRB Array Tools http://linus.nci.nih.gov/BRB-ArrayTools.html. The raw data set was filtered according to a standard procedure to exclude spots below a minimum intensity of 20 in both fluorescence channels. If the fluorescence intensity of one channel was higher than 20 , but the other was below 20, the fluorescence of the low intensity 
channel was arbitrarily set to 20. Flagged spots were also excluded from the analysis. A total of 33757 genes passed the filter and were used for the analysis.

\section{Real Time PCR Analysis}

A total of $0.5 \mu \mathrm{g}$ of purified RNA was used to synthesize cDNA using Random Hexamers (Qiagen, Valencia, CA, USA) and Superscript II RT (Invitrogen, Carlsbad, CA, USA) according to the manufacturer's instruction. The expression of CCL2, CCR7, CD209 and PIM1 were tested using specific TaqMan Gene Expression Assays (Applied Biosystems, Carlsbad, CA, USA). HPRT1 was selected as the housekeeping gene, due to the fact that it has been described as a housekeeping gene in monocytes [20] and it showed low variability in our microarray dataset. RT-PCR reactions were setup with TaqMan Universal PCR Master Mix (Applied Biosystems) in 384-well plates in a final reaction volume of $10 \mu \mathrm{l}$. PCR was conducted using a 7900 HT Sequence Detection System (Applied Biosystems) and data were analyzed using SDS 2.3 software package (Applied Biosystems).

\section{Statistical Analysis}

Class comparison was conducted with BRB Array Tools using a random variance model. Significant genes were defined as $p$-value $<0.001$ and FDR $<0.1$. Hierarchical cluster analysis and TreeView software were used for data visualization (Eisen Lab, http://rana.lbl.gov) [21]. Partek Genomic Suite 6.4 (Partek Inc., St. Louis, MO, USA) was used for the Principal Component Analysis. Database for Annotation, Visualization and Integrated Discovery (DAVID) 2008 software [22,23] was used for Gene Ontology (GO) enrichment analysis. For the analysis of specific pathways related to DC functions all the genes that, according to Biocarta (http://www.biocarta. com), are part of a specific pathway were selected. For each pathway, similarly to Chaussabel et al 2008 [24] a less stringent $p$-value (0.05) and FDR (0.15) filter was applied and the remaining number of genes was arithmetically computed according to their up/downregulation.

\section{Results}

\section{GM-CSF and 15 kDa Granulysin induce partially} overlapping monocyte signatures

Elutriated monocytes were cultured in presence of GMCSF $(10 \mathrm{ng} / \mathrm{ml}, 56 \mathrm{IU} / \mathrm{ml}$ ) or $15 \mathrm{kDa}$ Granulysin (10 nM). At 4, 12, 24 and 48 hours RNA was isolated and used for global gene expression analysis. Principal component analysis of the entire dataset (Figure 1a) revealed that GM-CSF and $15 \mathrm{kDa}$ Granulysin induced a response in monocytes that was similar at early time points ( 4 hours) but strongly differed at later time points (12, 24 and 48 hours). In particular, principal component (PC) \#1 which accounted for $31.5 \%$ of the variability of the dataset did not separate the samples cultured with Granulysin from those cultured with GMCSF, but clearly placed the 4 and 48 hour samples at the extremes with the other samples in between and closer to the 48 hour samples. This indicated that the two agents induced one group of genes at 4 hours and a second set at later times. PC \#2, which accounted for $14.8 \%$ of the variability, split the GM-CSF and Granulysin samples into two distinct groups at later time points, indicating that the differences between the GM-CSFand Granulysin-cultured monocytes became more evident at later time points. The third PC $(14.1 \%$ of the variability) segregated time 0 samples, the untreated monocytes, from the other samples indicating that both agents induced major changes at the transcriptome level when compared to time 0 samples.

In order to stratify changed transcripts associated with treatment and time in an unbiased fashion, the complete gene set was further filtered to include genes with expression levels $\geq 1.75$-fold from the median in at least $20 \%$ of the samples [25]. 9951 out of 33757 genes were obtained and used for an unsupervised hierarchical cluster analysis which clearly separated early time point samples (T0 and T4) from the late time point samples (Figure 1b). Moreover, within the cluster of the late time point samples, three subclusters emerged: all 12-hour samples, the late $15 \mathrm{KDa}$ Granulysin and late GM-CSF samples. This analysis revealed that GM-CSF and Granulysin induce in monocytes similar changes at the transcriptome level at early time points, but differences become more evident at later time points.

\section{GM-CSF and $15 \mathrm{kDa}$ Granulysin induce the expression of} several genes related to apoptosis and cell differentiation To analyze genes significantly induced by both GM-CSF and Granulysin compared to time 0 monocytes, we selected only the genes that at each time point were commonly induced following treatment by both agents compared to time 0 monocytes ( $\mathrm{t}$-test with $\mathrm{p}$-value $<0.001$ and FDR < 0.1). A total of 3191, 2416, 1534 and 1738 genes were induced by both GM-CSF and Granulysin at 4, 12,24 and 48 hours respectively. We then evaluated gene ontology (GO) families that were statistically overrepresented among up- and down-regulated genes at each time point (Figure 2a, b, c, d). Genes related to apoptosis and cell differentiation were significantly enriched at almost all time points. In particular, genes that negatively regulate apoptosis were up-regulated at 4 hours, whereas at later time points those involved with positive induction of apoptosis were mainly down-regulated, suggesting a general down-regulation of apoptosis at each time point. The opposite was observed regarding proliferation related genes, with proliferation related genes mainly up-regulated 


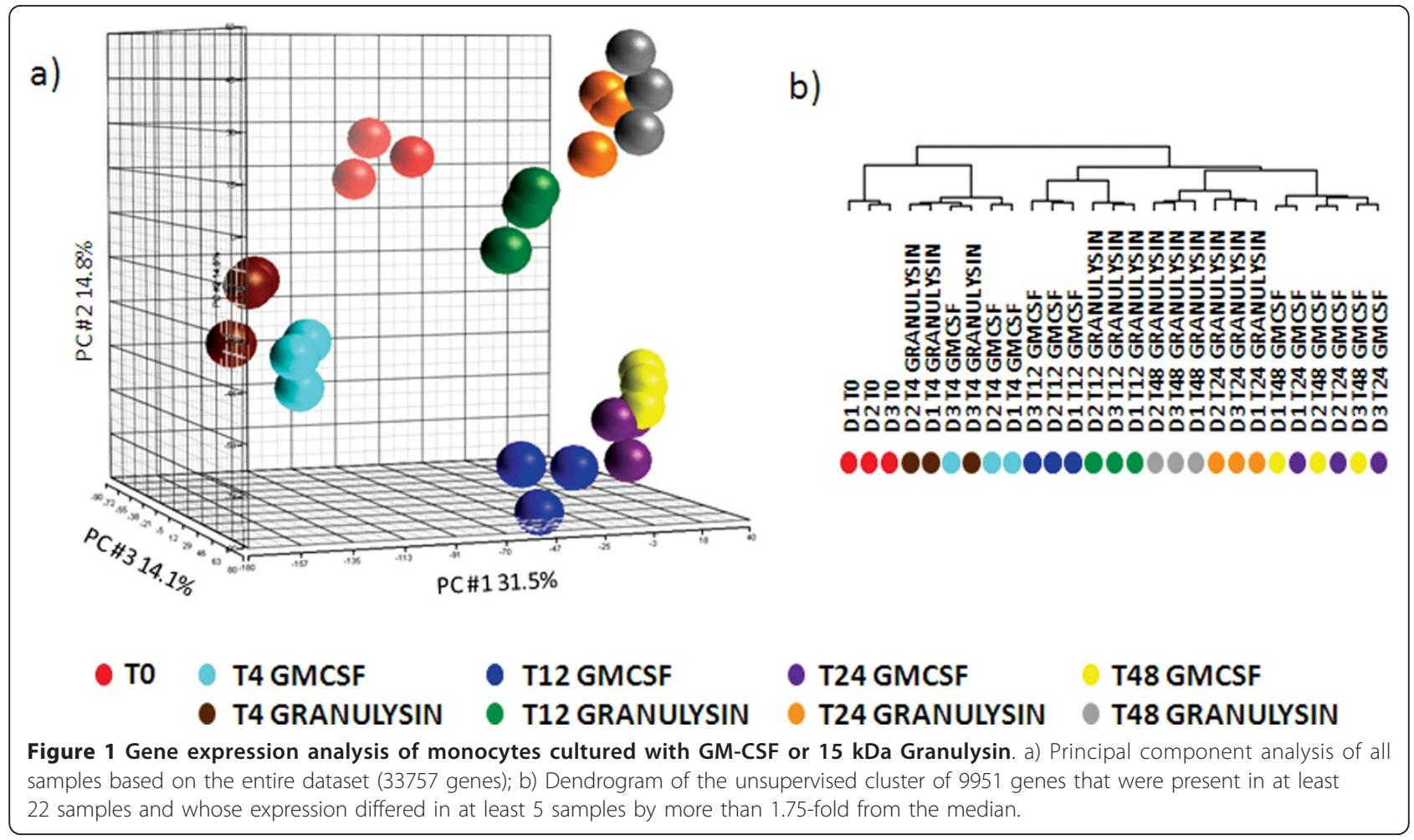

at 4 hours and the negative regulation of proliferation related genes down-regulated at later time points, pointing to a general induction of cell proliferation. Moreover, at later time points, genes encoding zinc finger proteins were up-regulated and those encoding ribosomal proteins were down-regulated. Interestingly, at 12 hours both GM-CSF and Granulysin induced genes related to the regulation of the adaptive immune response, including CD40, CD80, PVR, PVRL2 and IDO1. This initial activation of the immune system was followed at 24 and 48 hours by the down-regulation of genes involved in leukocyte activation and proliferation, such as IL-8, IL-15, RAB27A, BCL11, FYN and CLCF1.

\section{The GM-CSF-specific gene expression signature}

To identify genes specifically induced by GM-CSF at each time point we selected only the genes that were differentially expressed ( $p$-value $<0.001$ and FDR $<0.1$ ) by GMCSF-treated monocytes versus both time 0 monocytes and cells treated with Granulysin at the same time points. A total of $98,768,756$ and 467 genes were specifically induced in GM-CSF-treated monocytes at 4, 12, 24 and 48 hours, respectively (Figure 3 ). Gene functional categories defined by Gene Ontology (GO) families at each time point were analyzed and only those overrepresented in both up- and down-regulated genes were illustrated (Figure 3). Interestingly, GM-CSF-treated monocytes specifically down-regulated immune related genes at each time point, among which were IL-10, CXCL1, CXCL2, CXCR4, CXCR5, and the co-stimulatory molecules CD27, CD28, FYB (ADAP) and TNFSF4 (OX40L). In particular, cytokine production, lymphocyte mediated immunity and humoral immune response GO families were overrepresented among the down-regulated genes at late time points. In contrast, at 48 hours, antigen processing and presentation were specifically up-regulated, including the overexpression of the genes CD1A, CD1B, CD1E, and HLA-DQA1. Moreover, at 12 hours, GM-CSF specifically up-regulated genes involved in myeloid cell differentiation, including IRF4, CSF1 (GCSF), RUNX1, CBFB and PPARG. In addition, at 12 hours, GM-CSF specifically induced the down-regulation of genes related to cell cycle arrest (among which were the cyclin-dependent kinase inhibitors CDKN1B, CDKN2B, CDNK1C), and thus favored cell proliferation. However, at 48 hours, anti-apoptotic genes, such as PIM3, THBS1, HGF and SERPINB2, were mainly down-regulated. Additionally, among the up-regulated genes specifically induced by GM-CSF at early time points were angiogenesis genes, while at late time points lipid biosynthetic process genes were up-regulated and several histone genes were downregulated.

The $15 \mathrm{kDa}$ Granulysin-specific gene expression signature A total of 152, 498, 429 and 598 genes were specifically induced in Granulysin treated monocytes at 4, 12, 24 and 
a)

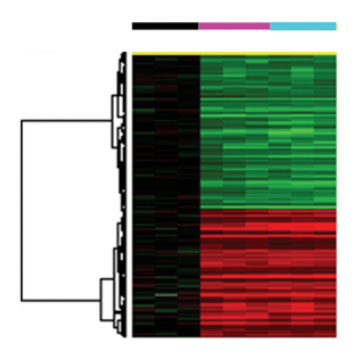

b)

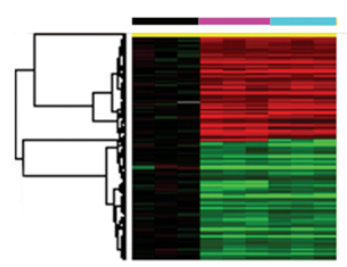

c)

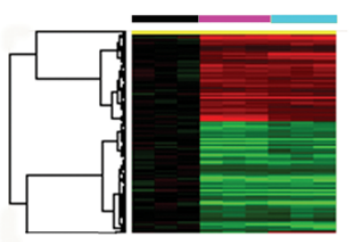

d)

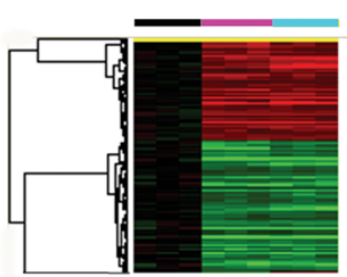

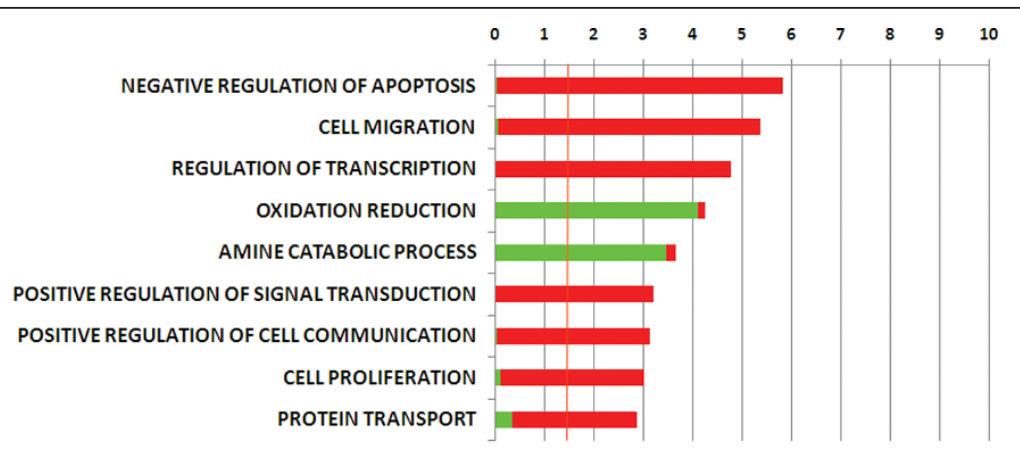
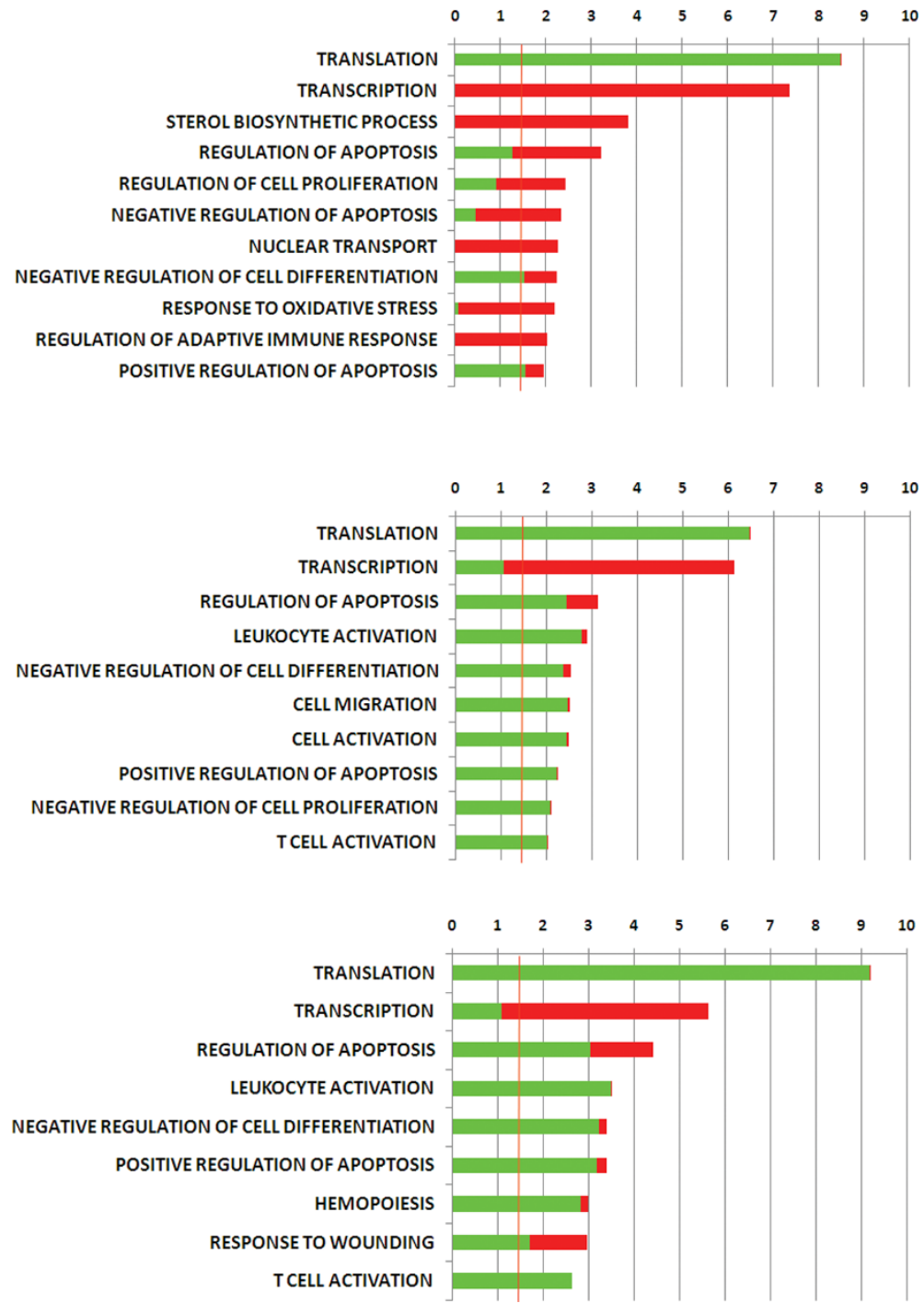

Figure 2 Monocyte genes induced by both GM-CSF and 15 kDa granulysin. Hierarchical clustering of the 3191, 2416, 1534 and 1738 genes induced by both factors at 4 (a), 12 (b), 24 (c) and 48 (d) hours respectively (p-value $<0.001$, FDR $<0.1$ ) and the related GO analysis. The

hierarchical clustering was T0 corrected; the black bar indicates TO monocytes, the fuchsia bar GM-CSF-treated monocytes, and the light blue bar Granulysin-treated monocytes. GO analyses were made with DAVID. The bars indicate -Log10 of the p-value of the overrepresentation of genes induced in each GO family. Green bars indicate down-regulated genes, while red bars indicate up-regulated genes. The orange line indicates the threshold of statistical significance ( $p$-value $=0.05)$. 


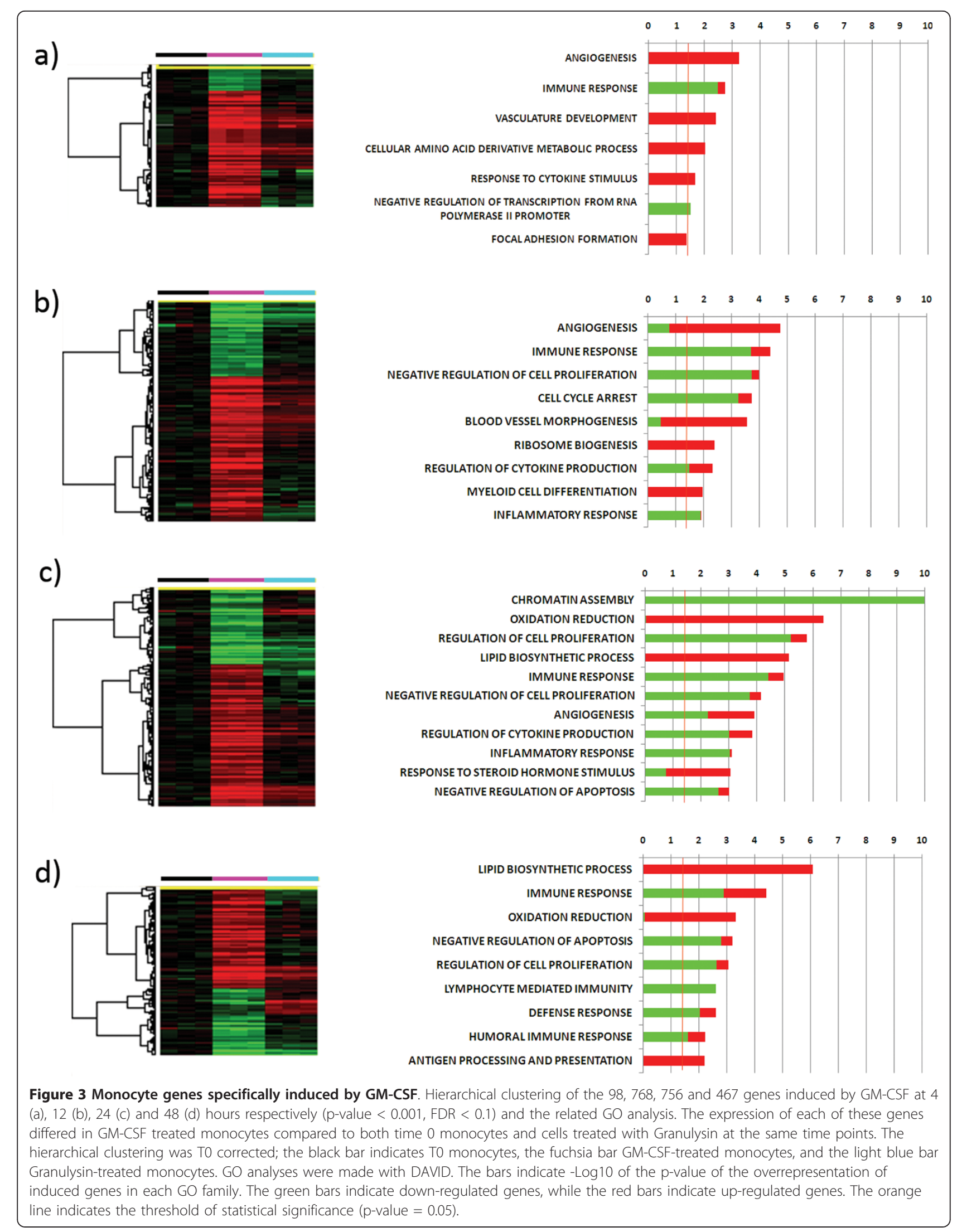


48 hours, respectively, versus both time 0 monocytes and cells treated with GM-CSF at the same time points ( $p$ value $<0.001$ and $\mathrm{FDR}<0.1$, Figure 4$)$. GO analysis showed immune response genes were up-regulated by Granulysin at each time point. In particular, a coordinated and time-dependent induction of immune related genes could be detected. At 12 hours, innate immunity related genes were up-regulated, but were later downregulated. At 48 hours humoral and lymphocyte proliferative genes were mostly up-regulated, including CCL2, TNFRSF4, CD38, EBI3, C2, and C3. In addition, cell adhesion genes, including 4 integrins (ITGB8, ITGA9, ITGAV, ITGB5) and the chemokine C-C motif receptor 7 (CCR7), were specifically up-regulated especially at late time points. In addition, chemotaxis related genes were up-regulated at almost all time points, although the involved genes changed markedly between 4 and 48 hours. In fact, CXCL1, CXCL11, CCL20 and IL-6 were up-regulated at 4 hours, whereas CXCL3, CXCL12, CCL2, CCRL2, NRP2 and SEMA3A were induced at 48 hours. Of special note was the induction of cell proliferation genes: after the negative regulation of cell proliferation genes at 4 hours, a positive regulation of cell proliferation genes was most prominent at 48 hours.

\section{Granulysin, but not GM-CSF, activated pathways are related to $D C$ function and common-host-response}

Since one of the main in vitro therapeutic uses of GMCSF is the differentiation, in combination with IL-4, of monocytes into DCs and considering that our results suggest a partially similar response of monocytes when cultured with GM-CSF or $15 \mathrm{kDa}$ Granulysin, we focused on 6 specific Biocarta pathways primarily involved in DC function (Figure 5). To evaluate the level of activation of each pathway we used gene lists with a less stringent cut off ( $p$-value $<0.05$ and FDR $<0.15$ ) [24] and calculated the percentage of genes in each pathway induced by each treatment versus T0 monocytes. GM-CSF- and Granulysin-treated monocytes showed a similar number of genes in the Antigen Processing and Presentation, and Monocyte and Surface Molecules Pathways, although the former pathway revealed a constant up-regulation of genes, whereas for the latter pathway a down-regulation at late time points. In contrast, differences were observed regarding the other four pathways, reinforcing the observations described above. GM-CSF-treated monocytes clearly showed a unique down-regulation of the IL-10 Anti-Inflammatory Signaling and the Co-stimulatory Signal during T-cell Activation Pathways, whereas Granulysin-treated monocytes showed an up-regulation of genes in the latter pathway as well as those in the IL-12 and Stat4 Dependent Signaling in Th1 Development and Dendritic Cells in Regulating Th1 and Th2 Development Pathways. Almost the same conclusions could be outlined by focusing on the fold change of the genes in each pathway instead of the percentage of genes (data not shown).

To validate the microarray data, we performed realtime PCR on CCL2, CCR7, PIM1 and CD209 genes. The selection of CCL2 and CCR7 was based on their up-regulation in Granulysin-treated, but not GM-CSFtreated monocytes in array data. PIM1 was selected because it has been described as being induced by GMCSF[26], and CD209 was selected since it is a marker of DC differentiation. The analysis was performed only on untreated T0 monocytes and hour 4 and 48 GM-CSFand Granulysin-treated monocytes. Both CCL2 and CCR7 were statistically up-regulated by both agents at 4 hours, however, at 48 hours they were only up-regulated by Granulysin ( $p$-value < 0.01) with a fold change greater than 70 for CCR7 and greater than 800 for CCL2 compared to time 0 monocytes, confirming the finding by microarray analysis (Additional file 1). At 4 hours the expression of both CCL2 and CCR7 was greater in Granulysin-treated monocytes than in monocytes treated with GM-CSF, with a fold change in Granulysin samples more than doubled for CCR7 and more than quadrupled for CCL2 compared to GM-CSF. Although PIM1 was filtered out in our analysis, RT-PCR showed a statistically significant induction of PIM1 at 48 hours ( $p$-value $<0.05$ ) by both GM-CSF and Granulysin, but its expression was greater in GM-CSF treated cells. This difference can be easily ascribed to the high stringency we used for statistical analysis of the microarray data $(p$-value $<0.001)$ where we preferred to select and analyze only those genes showing strong induction compared time 0 monocytes. In addition, we observed that CD209 was up-regulated by both agents at 48 hours ( $p$-value $<0.01$, with fold changes between 5 and 20 versus time 0 monocytes), which is similar to what we observed in the microarray dataset (both agents increased the expression CD209 genes with $p$-values < 0.0001).

\section{Discussion}

GM-CSF has been used for immunotherapy both in vivo and ex vivo because of its stimulatory effect on immune system cells. Its main application for ex vivo immunotherapy is the differentiation of monocytes into DCs [9]. The broad utilization of GM-CSF in experimental conditions as well as in clinical use is partially due to the lack of alternative agents with similar activity. In this study, we performed a functional characterization of 15 kDa Granulysin side by side with GM-CSF and reported their impact on gene expression changes and kinetics in monocytes. Considering the stronger reliability of analyses of functional modules of genes compared to the analysis of single genes $[24,27,28]$, we focused our 


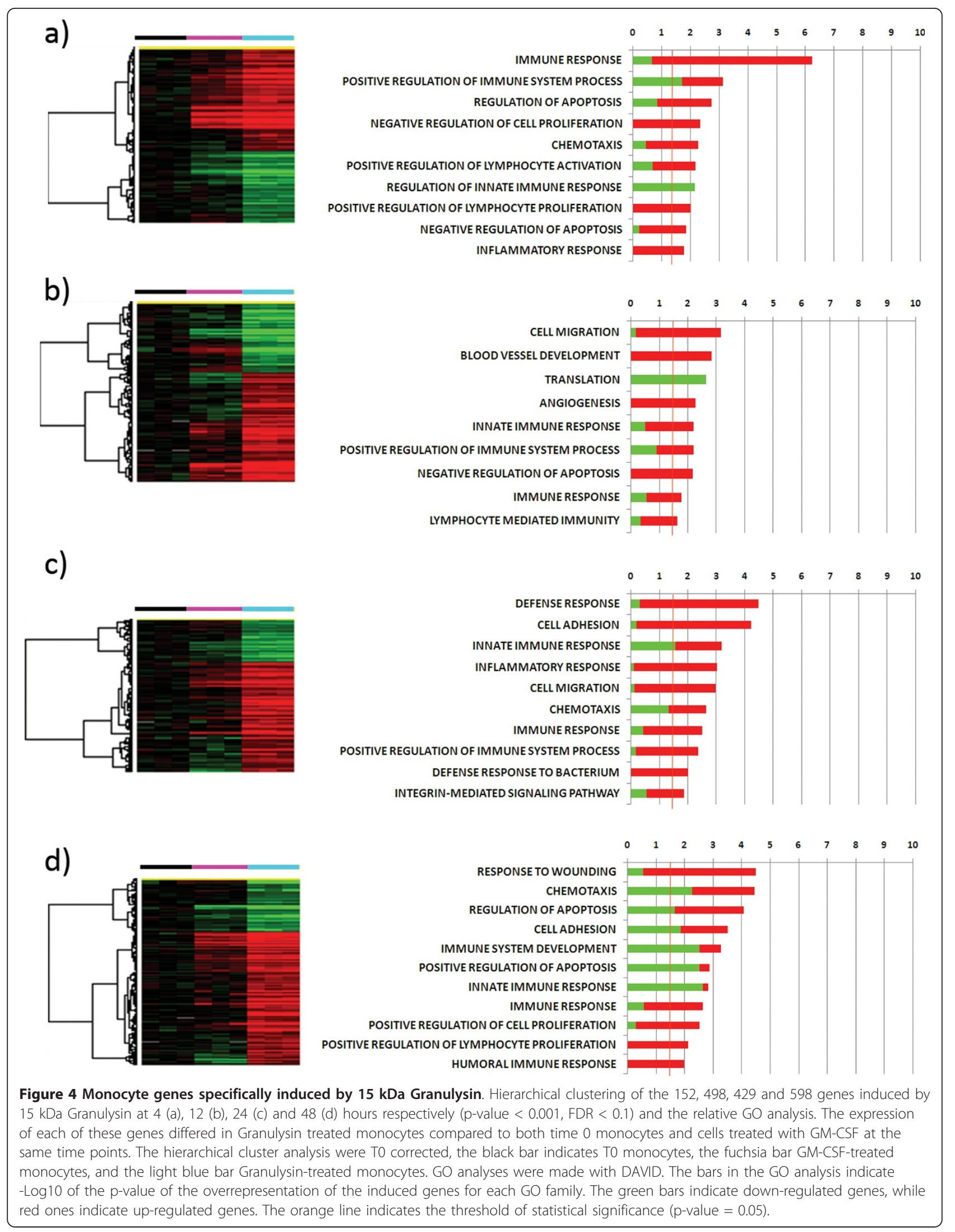




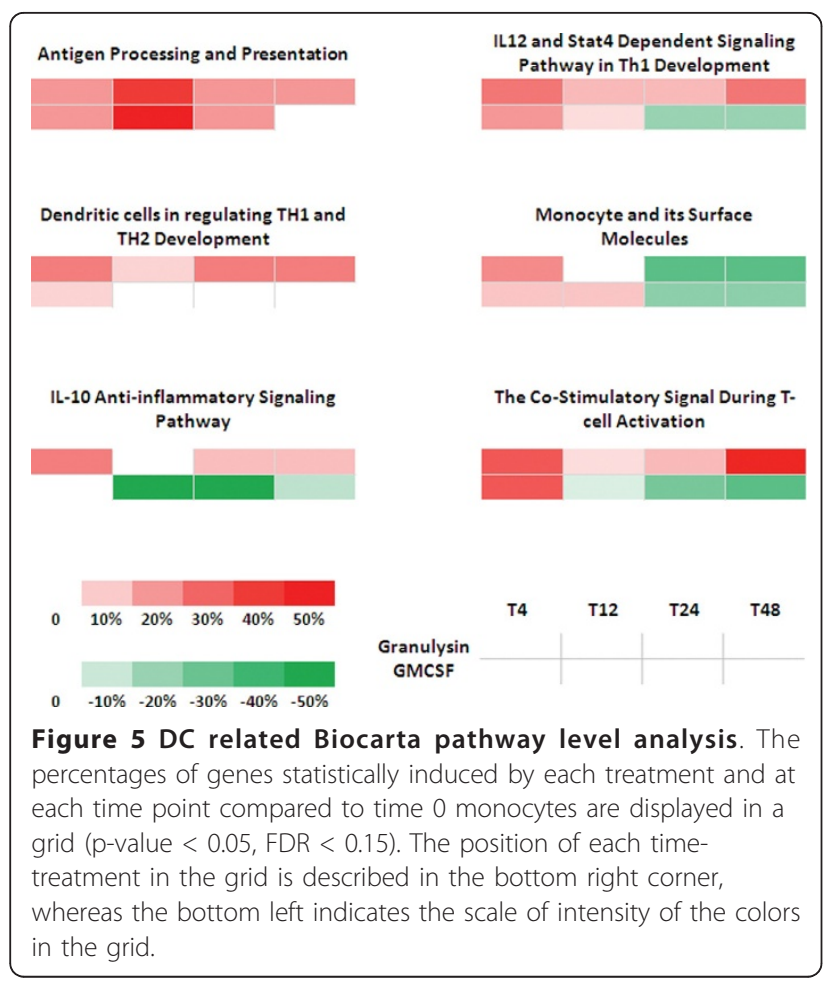

analysis only on the pathways overrepresented among genes differently expressed with highly stringent $p$-values. Although it could be argued that several genes were not included in the analysis due to the high stringency, the use of these criteria ensured high sensitivity and specificity[29].

Our analysis showed that GM-CSF and $15 \mathrm{kDa}$ Granulysin share similar functional property illustrated by their induction of large number of gene expression changes at different time points. The genes common to both agents were mainly related to cell differentiation and apoptosis; these genes enhanced the differentiation of monocytes and negatively impacted apoptosis. In addition, the common signature included immune response genes that were initially up-regulated in a similar fashion by both cytokines and were then down-regulated. However, beyond these overlapping functional characteristics, two different signatures specific to the agent were detected. The GM-CSFspecific signature revealed a down-regulation of immune response genes, among which were several co-stimulatory molecules. In contrast, Granulysin specifically and strongly induced genes related to the immune response with an initial activation on innate immune related genes followed by lymphocyte proliferative genes at later time points. In addition, cell adhesion genes were also specifically induced by Granulysin.

GM-CSF is a growth factor whose cellular effects had been studied for more than twenty years [30]. At low concentrations $(<1 \mathrm{pM})$ it induces only cell survival, but at higher concentrations it leads to monocyte proliferation, differentiation and functional activation [31]. We found that, although both GM-CSF and Granulysin induced genes related to cell differentiation and silenced genes related to cell death, only GM-CSF treated monocytes showed the down-regulation of cell cycle arrest genes, as previously described $[31,32]$ and the up-regulation of genes involved in the myeloid cell differentiation. Moreover, our gene expression analysis not only confirmed the induction by GM-CSF of previously described genes, such as the anti-apoptotic gene IRF4 [33], the proliferative gene PIM1 [26], CSF1 [34] and the macrophage inducer PPARG $[35,36]$; but also showed the up-regulation of the proliferation/differentiation regulator dimer RUNX1 -CBFB. RUNX1 -CBFB has not been previously reported to be upregulated by GM-CSF and this observation merits further investigation.

Monocytes cultured in presence of GM-CSF alone are able to differentiate into iDCs, although these iDCs show a reduced ability to induce an effective activation of lymphocytes after maturation [36-38]. Our gene expression analysis clearly showed that GM-CSF leads to a specific down-regulation of several immune-related genes. Although we observed that GM-CSF induced a specific up-regulation of the well-known CD1 family genes [13], which play an important role in lipid antigen presentation; gene profiling also revealed a specific down-regulation of the co-stimulatory genes CD27, CD28, FYB (ADAP) and TNFSF4 (OX40L). Recent studies have shown how the proteins encoded by these genes are fundamental for the interaction of monocyte-derived dendritic cells and $\mathrm{T}$ and B cells [39-44]. In particular, GM-CSF derived DCs show a reduced ability to secret IL-12 after maturation $[9,37]$. Consistent with this, we observed a general specific downregulation of the IL-12 and STAT4 Dependent Signaling Pathway in Th1 Development and the Co-stimulatory Signal during T-cell Activation Pathway. While these data suggest that GM-CSF treated monocytes might have a diminished ability to positively stimulate lymphocytes following antigen presentation, further focused functional studies are needed to test this hypothesis. Of particular interest is the observation that in the setting tested, GMCSF specifically down-regulated IL-10, both the gene and the pathway, whereas previous results suggest that monocytes cultured in presence of GM-CSF produce high amounts of IL-10 once stimulated with LPS, IFN- $\gamma$, TNF $\alpha$ or anti-CD40 Ab $[9,37]$. This discrepancy could be the result of the differences in the concentration of GM-CSF used in the monocyte culture conditions or it may be that the higher expression of IL-10 by GM-CSF cultured monocytes is only subsequent to the stimulation with maturating agents.

$15 \mathrm{kDa}$ Granulysin is constitutively secreted in vivo by CTL and NK cells, but its function is still incompletely 
defined [15,17]. The ability of Granulysin to replicate some GM-CSF-induced monocyte responses is shown by the observation that between 4 and 48 hours thousands of genes were induced by both GM-CSF- and Granulysin. On the other hand, the gene expression analysis revealed that Granulysin, but not GM-CSF, treated monocytes showed an overexpression of several immune-related genes at each time point. Moreover, our data showed that Granulysin induced a specific time-coordinated activation of the immune system. At early time points, several genes involved in the activation of the innate immune system were induced whereas, at later time points, lymphocyte proliferation genes and humoral immune response were up-regulated. In addition, the pathway analysis clearly demonstrated that Granulysin-treated monocytes specifically induced the IL-12 and Stat4 Dependent Signaling Pathway in Th1 Development, suggesting that Granulysin might induce a shift towards Th1 $\mathrm{T}$ cell differentiation.

Recently, co-stimulatory molecules have been shown to play a role in chemotaxis [45]. We found that, in contrast to GM-CSF-treatment, Granulysin treatment did not lead to the down-regulation of co-stimulatory molecules; rather Granulysin specifically showed an upregulation of the co-stimulatory pathways and overexpressed chemotactic genes at each time point. In particular, Granulysin induced the expression of a wide group of chemokines that are able to attract neutrophils (CXCL1, CXCL3) [46], memory and activated T cells (CXCL11, CCL20, CCR7) [47,48], monocytes (CCL2, CCL20) [49], macrophages and dendritic cells (NRP2) [50]. Several studies have shown that chemokines act synergistically [51,52], strengthening their signals and overcoming eventual antagonists secreted by pathogens $[53,54]$. Interestingly a partially overlapping timefashioned chemokine induction has been described by myeloid and plasmacytoid DCs exposed to influenza virus [55]. This observation might indicate that $15 \mathrm{kDa}$ Granulysin plays an important role in activating the immune system in response to pathogens by inducing monocytes to recruit other immune cells. Moreover, the observation that Granulysin acts as an alarmin strengthen this hypothesis $[16,18]$.

\section{Conclusions}

In conclusion, the analysis of gene expression profiles of monocytes cultured in presence of GM-CSF and $15 \mathrm{kDa}$ Granulysin revealed that although both induce many of the same genes, these two cytokines induce two different monocyte responses. Considering the greater induction of several immune related functions by $15 \mathrm{kDa}$ Granulysin, this study suggests that $15 \mathrm{kDa}$ Granulysin may prove a useful therapeutic immunomodulator for in vitro production of Th-1 polarized monocyte-derived DCs for adoptive immunotherapy.

\section{Additional material}

\begin{abstract}
Additional file 1: Quantitative real time PCR analysis of selected genes. Relative quantification of CCR7, CCL2, PIM1 and CD209 genes are represented. HPRT1 was used as a housekeeping gene. One sample of time 0 monocytes was set to the unitary value (1) and used as calibrator. Values from the 3 different donors were averaged and the standard deviation is represented for each bar. The light blue columns represent GM-CSF-treated monocytes and the purple bar Granulysin-treated monocytes.
\end{abstract}

\section{Acknowledgements and funding}

This work is supported by the Intramural Programs of the National Institutes of Health Clinical Center and National Cancer Institute.

\section{Author details}

${ }^{1}$ Cell Processing Section, Department of Transfusion Medicine, Clinical Center, National Institutes of Health, Bethesda, MD 20892, USA. ${ }^{2}$ Laboratory of Cellular and Molecular Biology, National Cancer Institute, National Institutes of Health, Bethesda, MD 20892, USA. ${ }^{3}$ Infectious Disease and Immunogenetics Section, Department of Transfusion Medicine, Clinical Center, and Center for Human Immunology $(\mathrm{CHI})$, National Institutes of Health, Bethesda, MD 20892, USA.

\section{Authors' contributions}

LC performed experiments and data analysis; MWF expressed and purified the $15 \mathrm{kDa}$ Granulsyin; DFS, MS, FMM, EW, CC, AMK contributed to experimental design and data analysis; LC, DFS compiled the manuscript; MS, FMM, EW, CC, AMK revised the manuscript. All of the authors have read and approved the final manuscript.

\section{Competing interests}

AMK and CC hold patents on granulysin. The remaining authors declare no competing interests.

Received: 10 March 2011 Accepted: 18 April 2011

Published: 18 April 2011

\section{References}

1. Waller EK: The role of sargramostim (rhGM-CSF) as immunotherapy. Oncologist 2007, 12(Suppl 2):22-26.

2. Everly JJ, Lonial S: Immunomodulatory effects of human recombinant granulocyte-macrophage colony-stimulating factor (rhuGM-CSF): evidence of antitumour activity. Expert Opin Biol Ther 2005, 5:293-311.

3. Mitsuyasu RT, Golde DW: Clinical role of granulocyte-macrophage colonystimulating factor. Hematol Oncol Clin North Am 1989, 3:411-425.

4. Boyer MW, Waller EK, Bray RA, Unangst T, Johnson TS, Phillips C, Jurickova I, Winton EF, Yeager AM: Cytokine upregulation of the antigen presenting function of acute myeloid leukemia cells. Leukemia 2000, 14:412-418.

5. Arellano ML, Langston A, Winton E, Flowers CR, Waller EK: Treatment of relapsed acute leukemia after allogeneic transplantation: a single center experience. Biol Blood Marrow Transplant 2007, 13:116-123.

6. Sallusto F, Lanzavecchia A: Efficient presentation of soluble antigen by cultured human dendritic cells is maintained by granulocyte/ macrophage colony-stimulating factor plus interleukin 4 and downregulated by tumor necrosis factor alpha. J Exp Med 1994, 179:1109-1118.

7. Mohamadzadeh M, Berard F, Essert G, Chalouni C, Pulendran B, Davoust J, Bridges G, Palucka AK, Banchereau J: Interleukin 15 skews monocyte differentiation into dendritic cells with features of Langerhans cells. J Exp Med 2001, 194:1013-1020.

8. Santini SM, Lapenta C, Logozzi M, Parlato S, Spada M, Di PT, Belardelli F: Type I interferon as a powerful adjuvant for monocyte-derived dendritic 
cell development and activity in vitro and in Hu-PBL-SCID mice. J Exp Med 2000, 191:1777-1788.

9. Conti L, Gessani S: GM-CSF in the generation of dendritic cells from human blood monocyte precursors: recent advances. Immunobiology 2008, 213:859-870

10. Lehmann MH: Recombinant human granulocyte-macrophage colonystimulating factor triggers interleukin-10 expression in the monocytic cell line U937. Mol Immunol 1998, 35:479-485.

11. Smith WB, Guida L, Sun Q, Korpelainen El, van den HC, Gillis D, Hawrylowicz CM, Vadas MA, Lopez AF: Neutrophils activated by granulocyte-macrophage colony-stimulating factor express receptors for interleukin-3 which mediate class II expression. Blood 1995, 86:3938-3944.

12. Alderson MR, Tough TW, Ziegler SF, Armitage RJ: Regulation of human monocyte cell-surface and soluble CD23 (Fc epsilon RII) by granulocytemacrophage colony-stimulating factor and IL-3. J Immunol 1992, 149:1252-1257.

13. Kasinrerk W, Baumruker T, Majdic O, Knapp W, Stockinger H: CD1 molecule expression on human monocytes induced by granulocyte-macrophage colony-stimulating factor. J Immunol 1993, 150:579-584.

14. Hornell TM, Beresford GW, Bushey A, Boss JM, Mellins ED: Regulation of the class II MHC pathway in primary human monocytes by granulocytemacrophage colony-stimulating factor. J Immunol 2003, 171:2374-2383.

15. Hanson DA, Kaspar AA, Poulain FR, Krensky AM: Biosynthesis of granulysin, a novel cytolytic molecule. Mol Immunol 1999, 36:413-422.

16. Zitvogel L, Kroemer G: The multifaceted granulysin. Blood 2010, 116:3379-3380

17. Krensky AM, Clayberger C: Biology and clinical relevance of granulysin. Tissue Antigens 2009, 73:193-198.

18. Tewary P, Yang D, de la RG, Li Y, Finn MW, Krensky AM, Clayberger C, Oppenheim Jj: Granulysin activates antigen-presenting cells through TLR4 and acts as an immune alarmin. Blood 2010, 116:3465-3474.

19. Finn MW, Clayberger C, Krensky AM: Expression and purification of $15 \mathrm{kDa}$ granulysin utilizing an insect cell secretion system. Protein Expr Purif 2011, 75:70-74.

20. Mane VP, Heuer MA, Hillyer P, Navarro MB, Rabin RL: Systematic method for determining an ideal housekeeping gene for real-time PCR analysis. J Biomol Tech 2008, 19:342-347.

21. Eisen MB, Spellman PT, Brown PO, Botstein D: Cluster analysis and display of genome-wide expression patterns. Proc Natl Acad Sci USA 1998, 95:14863-14868.

22. Huang dW, Sherman BT, Zheng $X$, Yang J, Imamichi T, Stephens $R$, Lempicki RA: Extracting biological meaning from large gene lists with DAVID. Curr Protoc Bioinformatics 2009, 13, Unit.

23. Dennis G Jr, Sherman BT, Hosack DA, Yang J, Gao W, Lane HC, Lempicki RA: DAVID: Database for Annotation, Visualization, and Integrated Discovery. Genome Biol 2003, 4:3.

24. Chaussabel D, Quinn C, Shen J, Patel P, Glaser C, Baldwin N, Stichweh D, Blankenship D, Li L, Munagala I, et al: A modular analysis framework for blood genomics studies: application to systemic lupus erythematosus. Immunity 2008, 29:150-164.

25. Simon R: Using DNA microarrays for diagnostic and prognostic prediction. Expert Rev Mol Diagn 2003, 3:587-595.

26. Guthridge MA, Barry EF, Felquer FA, McClure BJ, Stomski FC, Ramshaw H, Lopez AF: The phosphoserine-585-dependent pathway of the GM-CSF/L3/L-5 receptors mediates hematopoietic cell survival through activation of NF-kappaB and induction of bcl-2. Blood 2004, 103:820-827.

27. Mootha VK, Lindgren CM, Eriksson KF, Subramanian A, Sihag S, Lehar J, Puigserver P, Carlsson E, Ridderstrale M, Laurila E, et al: PGC-1alpharesponsive genes involved in oxidative phosphorylation are coordinately downregulated in human diabetes. Nat Genet 2003, 34:267-273.

28. Segal MR, Dahlquist KD, Conklin BR: Regression approaches for microarray data analysis. J Comput Biol 2003, 10:961-980.

29. Shi L, Jones WD, Jensen RV, Harris SC, Perkins RG, Goodsaid FM, Guo L, Croner $L$, Boysen $C$, Fang $H$, et al: The balance of reproducibility, sensitivity, and specificity of lists of differentially expressed genes in microarray studies. BMC Bioinformatics 2008, 9(Suppl 9):S10.

30. Hamilton JA: Colony-stimulating factors in inflammation and autoimmunity. Nat Rev Immunol 2008, 8:533-544.

31. Guthridge MA, Powell JA, Barry EF, Stomski FC, McClure BJ, Ramshaw H, Felquer FA, Dottore M, Thomas DT, To B, et al: Growth factor pleiotropy is controlled by a receptor Tyr/Ser motif that acts as a binary switch. EMBO J 2006, 25:479-489.

32. Williams GT, Smith CA, Spooncer E, Dexter TM, Taylor DR: Haemopoietic colony stimulating factors promote cell survival by suppressing apoptosis. Nature 1990, 343:76-79.

33. Lehtonen A, Matikainen S, Miettinen M, Julkunen I: Granulocytemacrophage colony-stimulating factor (GM-CSF)-induced STAT5 activation and target-gene expression during human monocyte/ macrophage differentiation. J Leukoc Biol 2002, 71:511-519.

34. Gruber MF, Gerrard TL: Production of macrophage colony-stimulating factor (M-CSF) by human monocytes is differentially regulated by GMCSF, TNF alpha, and IFN-gamma. Cell Immunol 1992, 142:361-369.

35. Ricote M, Huang J, Fajas L, Li A, Welch J, Najib J, Witztum JL, Auwerx J, Palinski W, Glass CK: Expression of the peroxisome proliferator-activated receptor gamma (PPARgamma) in human atherosclerosis and regulation in macrophages by colony stimulating factors and oxidized low density lipoprotein. Proc Natl Acad Sci USA 1998, 95:7614-7619.

36. Skorokhod OA, Alessio M, Mordmuller B, Arese P, Schwarzer E: Hemozoin (malarial pigment) inhibits differentiation and maturation of human monocyte-derived dendritic cells: a peroxisome proliferator-activated receptor-gamma-mediated effect. J Immunol 2004, 173:4066-4074.

37. Ganguly D, Paul K, Bagchi J, Rakshit S, Mandal L, Bandyopadhyay G, Bandyopadhyay S: Granulocyte-macrophage colony-stimulating factor drives monocytes to CD14low CD83+ DC. Immunology 2007, 121:499-507.

38. Chitta S, Santambrogio L, Stern LJ: GMCSF in the absence of other cytokines sustains human dendritic cell precursors with $\mathrm{T}$ cell regulatory activity and capacity to differentiate into functional dendritic cells. Immunol Lett 2008, 116:41-54

39. Lippert U, Zachmann K, Ferrari DM, Schwarz H, Brunner E, Mahbub-UI Latif $A H$, Neumann C, Soruri A: CD137 ligand reverse signaling has multiple functions in human dendritic cells during an adaptive immune response. Eur J Immunol 2008, 38:1024-1032.

40. Hashimoto-Okada M, Kitawaki T, Kadowaki N, Iwata S, Morimoto C, Hori T, Uchiyama T: The CD70-CD27 interaction during the stimulation with dendritic cells promotes naive CD4(+) T cells to develop into T cells producing a broad array of immunostimulatory cytokines in humans. Int Immunol 2009, 21:891-904.

41. Hendriks J, Xiao Y, Rossen JW, van der Sluiis KF, Sugamura K, Ishii N, Borst J: During viral infection of the respiratory tract, CD27, 4-1BB, and OX40 collectively determine formation of CD8+ memory $T$ cells and their capacity for secondary expansion. J Immunol 2005, 175:1665-1676.

42. Wang J, Guo Z, Dong Y, Kim O, Hart J, Adams A, Larsen CP, Mittler RS, Newell KA: Role of 4-1BB in allograft rejection mediated by CD8+ T cells. Am J Transplant 2003, 3:543-551.

43. Croft M, So T, Duan W, Soroosh P: The significance of OX40 and OX40L to T-cell biology and immune disease. Immunol Rev 2009, 229:173-191.

44. Zhang X, Voskens CJ, Sallin M, Maniar A, Montes CL, Zhang Y, Lin W, Li G, Burch $E$, Tan M, et al: CD137 promotes proliferation and survival of human B cells. J Immunol 2010, 184:787-795.

45. Zhong W, Zhang Z, Hinrichs D, Wu X, Hall M, Xia Z, Rosenbaum JT: OX40 induces CCL20 expression in the context of antigen stimulation: an expanding role of co-stimulatory molecules in chemotaxis. Cytokine 2010, 50:253-259.

46. Scimone ML, Lutzky VP, Zittermann SI, Maffia P, Jancic C, Buzzola F, Issekutz AC, Chuluyan HE: Migration of polymorphonuclear leucocytes is influenced by dendritic cells. Immunology 2005, 114:375-385.

47. Sallusto F, Schaerli P, Loetscher P, Schaniel C, Lenig D, Mackay CR, Qin S, Lanzavecchia A: Rapid and coordinated switch in chemokine receptor expression during dendritic cell maturation. Eur J Immunol 1998, 28:2760-2769.

48. Schutyser E, Struyf S, Van DJ: The CC chemokine CCL20 and its receptor CCR6. Cytokine Growth Factor Rev 2003, 14:409-426.

49. Deshmane SL, Kremlev S, Amini S, Sawaya BE: Monocyte chemoattractant protein-1 (MCP-1): an overview. J Interferon Cytokine Res 2009, 29:313-326.

50. Rey-Gallardo A, Escribano C, Delgado-Martin C, Rodriguez-Fernandez JL, Gerardy-Schahn R, Rutishauser U, Corbi AL, Vega MA: Polysialylated neuropilin-2 enhances human dendritic cell migration through the basic C-terminal region of CCL21. Glycobiology 2010, 20:1139-1146.

51. Vanbervliet B, Bendriss-Vermare N, Massacrier C, Homey B, de Bouteiller O, Briere F, Trinchieri G, Caux C: The inducible CXCR3 ligands control plasmacytoid dendritic cell responsiveness to the constitutive 
chemokine stromal cell-derived factor 1 (SDF-1)/CXCL12. J Exp Med 2003, 198:823-830.

52. Gouwy M, Struyf S, Proost P, Van Damme J: Synergy in cytokine and chemokine networks amplifies the inflammatory response. Cytokine Growth Factor Rev 2005, 16:561-580.

53. Rosenkilde MM: Virus-encoded chemokine receptors-putative novel antiviral drug targets. Neuropharmacology 2005, 48:1-13.

54. Alcami A, Saraiva M: Chemokine binding proteins encoded by pathogens. Adv Exp Med Biol 2009, 666:167-179.

55. Piqueras B, Connolly J, Freitas H, Palucka AK, Banchereau J: Upon viral exposure, myeloid and plasmacytoid dendritic cells produce 3 waves of distinct chemokines to recruit immune effectors. Blood 2006, 107:2613-2618.

doi:10.1186/1479-5876-9-41

Cite this article as: Castiello et al: $15 \mathrm{kDa}$ Granulysin versus GM-CSF for monocytes differentiation: analogies and differences at the transcriptome level. Journal of Translational Medicine 2011 9:41.

\section{Submit your next manuscript to BioMed Central} and take full advantage of:

- Convenient online submission

- Thorough peer review

- No space constraints or color figure charges

- Immediate publication on acceptance

- Inclusion in PubMed, CAS, Scopus and Google Scholar

- Research which is freely available for redistribution

Submit your manuscript at www.biomedcentral.com/submit 